\title{
The Intestinal Microflora of Bullfrog Rana catesbeiana at Different Stages of its Development
}

\author{
Haruo Sugita, * Toshiyuki NaKajIma, ${ }^{*}$ and Yoshiaki Deguchi* \\ (Accepted July 7, 1984)
}

\begin{abstract}
Microflora in the contents of intestinal tracts of Bullfrog at different stages of its development was investigated using 7 different agar media, and major bacterial components were as follows: Tadepoles, Bacteroides A-like, other Bacteroidaceae, helically coiled and filamentous rods, Pseudomonas, A. hydrophila and pin-hole colony formers; metamorphosing tadpoles with hind legs, Bacteroides A-like, other Bacteroidaceae, Clostridium and pin-hole colony formers; frogs, Bacteroidaceae, Clostridium, $C$. freundii, $C$. diversus, $E$. coli, $E$. hafniae, $K$. pneumoniae, $A$. hinshawii and $P$. shigelloides. The differences of the intestinal microflora may depend on the changes of physiological conditions of host animals, and it is found that frogs is an important experimental animal to study the interaction between the intestinal microflora and host animals.
\end{abstract}

Recently ecological studies on gastrointestinal bacteria of freshwater animals have been performed. Sugrta et al..$^{1-8)}$ studied the microflora of gastrointestinal tracts of soft-shelled turtle Trionyx sinensis and found that the gastrointestinal microflora of the turtle differs significantly from that of freshwater fishes studied. The result suggest that there are some specific relationships between animals and their gastrointestinal microflora as recognized in higher animals. ${ }^{\text {) }}$ Also, this may reflect their habitats as fishes live in water and turtles on land. Frogs are adapted to live in fresh water and in moist places on land. When a tadpole transforms into a frog, its morphology and physiological functions change dramatically; that is, the mouth widens, the lungs develop, the intestine shortens and the gills and tail are resorted. In the metamorphosis of the frog, food habit also changes from herbivous or omnivorous form to carnivorous. Thus, the comparison of the intestinal microflora of frogs at different developmental stages may be a clue to analyze the relationship between intestinal bacteria and their hosts including lower to higher animals.

Bullfrog Rana catesbeiana were transplanted from North America into Japan as human food. However, it is recently used extensively as experimental animals in research rather than as food. Few studies on the intestinal bacteria as symbiota of this animals have been reported although many pathological and clinical researchs have been carried out. $^{5-8)}$ In the present paper we shall describe the results of qualitative and quantitative investigations of the intestinal microflora of the tadpole, metamorphosing tadpole and frog of Bullfrog.

\section{Materials and Methods}

Animals

Tadpoles of Bullfrog were purchased from a dealer and reared in 500-l plastic tanks containing tap water, indoor of our laboratory. The tadpole transformed into a frog within half a year. The tadpole and metamorphosing tadpole with hind legs were fed boiled spinach. The frog after metamorphosis were fed millworm Tenebrio molitor which was purchased from a dealer. Five tadpoles (10.3-19.5 g in body weight), 5 metaphorphosing tadoples (10.1-23.1 g) and 5 frogs (13.2-24.0 g) were used for bacteriological examination. No symptoms of disease were not observed on all animals.

\section{Bacteriological Sampling}

Each animal was pithed and its abdominal cavity was opened aseptically. The intestine was aseptically removed to a sterile petri dish. The content was weighed and placed in a test tube and a suitable amount of diluent was added to effect a tenfold dilution. The millworm was homogenized with 9 volumes of diluent and a tenfold dilution of specimen was prepared. The diluent solution is a phosphate buffer solution ( $\mathrm{pH}$ 7.6) containing

* Department of Fisheries, College of Agriculture and Veterinary Medicine, Nihon University, Shimouma 3, Setagaya, Tokyo 154, Japan (杉田治男・中島利之・出口吉昭：日本大学暞缺医学部水産学科). 
$0.05 \%$ L-cysteine hydrochloride and $0.1 \%$ agar reported by MITSUOKA. ${ }^{\theta}$ The sample was then vigorously vibrated with a vortex type mixer for $2 \mathrm{~min}$, diluted serially and plated onto 7 different agar media. The media included Trypticase soy blood agar [TS] (BBL), DHL agar (Eiken), Phenylethyl alcohol blood agar [PEA] (BBL), EG blood agar (Nissui), BL blood agar (Eiken), NBGT blood agar" ${ }^{\text {2) }}$ and FM-CW blood agar (Eiken). The inoculated TS, DHL and PEA plates were aerobically and EG, BL, NBGT and FM-CW plates were anaerobically incubated, both at $25^{\circ} \mathrm{C}$ for 7-8 days. Anaerobiosis was established by evacuating the atmosphere of an anaerobic jar containing steel wool which was activated by an acidic cupric sulfate and replacing the atmosphere with $\mathrm{CO}_{2}$ gas. ${ }^{\theta}$ )

After incubation, colonies that appeared on each plate were counted and viable count (i.e., colony forming unit) per $\mathrm{g}$ was obtained.

\section{Identification of Bacteria}

After the viable count was determined, colonies were divided into some types according to colonial characteristics. Three representatives of each colony type were plated onto TS or EG agar and purified by a second streaking onto the same medium.

Identification of the bacteria isolated aerobically were facilitated by examination of morphology and pigment production of the colony, as well as examination of the shape, spore formation, arrangement, staining characteristics and motility of the cells. In addition, the ability of the isolate to produce oxidase and catalase, to grow anaerobically and to metabolize glucose fermentatively or oxidatively was tested. Gram-negative bacteria were identified into generic levels by the modified scheme $^{10)}$ of SHEWAN et al., ${ }^{11)}$ and gram-positive bacteria were identified according to CowAN. ${ }^{12}$ ) Vibrionaceae was examined on sensitivity to vibrio static compound, O/129. Furthermore, gramnegative glucose-fermenting bacteria were identified by specific level using the Minitek system (BBL).

The obligate and facultative anaerobes isolated anaerobically were classified on the basis of gram reaction, cellular morphology, spore formation, and the ability to grow aerobically.

\section{Results}

Viable Counts of Bacteria

The number of viable bacteria recovered when the contents of the intestinal tracts of Bullfrog and its diet were sampled, was measured. Plate viable counts anaerobically incubated $\left(10^{8}-10^{8} \mathrm{~g}^{-1}\right)$ were larger than those aerobically incubated $\left(10^{5}-\right.$ $10^{8} \mathrm{~g}^{-1}$ ) at each developmental stage of the frog. Plate viable counts of the millworm incubated under aerobic and anaerobic conditions were $10^{\text {r }}$ $\mathrm{g}^{-1}$ with the exception of NBGT $\left(10^{3} \mathrm{~g}^{-1}\right)$ and DHL agars $\left(10^{8} \mathrm{~g}^{-1}\right)$.

\section{Generic Composition of Bacteria}

A total of 759 strains of aerobic and facultatively anaerobic bacteria was isolated aerobically from the intestinal tracts of Bullfrog and its diet. These were divided into 12 groups, Pseudomonas, Vibrio-Aeromonas group, Enterobacteriaceae, Moraxella, Acinetobacter, Flavobacterium, Bacillus, coryneforms, Micrococcus, Staphylococcus, Streptococcus and pin-hole colony formers. Almost all strains of Pseudomonas were incapable to utilized glucose, and the pin-hole colony formers, viability of which lost on subculture, were gramnegative rods.

A total of 703 strains of obligately anaerobic bacteria isolated from the intestinal tracts of Bullfrog was divided into 4 groups, Bacteroidaceae, Clostridium, helically coiled rods and filamentous rods. The later 2 components were both gramnegative bacteria, and the Bacterioidaceae included the bacterium similar to Bacteroides type A reported in freshwater fishes. ${ }^{13)}$ In the present paper we called it "Bacteroides A-like". No obligate anaerobes were isolated from the millworm.

\section{Specific Composition of the Enterobacteriaceae and Vibrionaceae}

A total of 122 strains of the Enterobacteriaceae and 78 strains of the Vibrionaceae were identified using the Minitek system. The former were divided into 10 species, Citrobacter freundii, $C$. diversus, Enterobacter cloacae, E. hafniae, Escherichia coli, Klebsiella pneumoniae, K. ozaenae, Arizona hinshawii and Serratia marcescens. The later was divided into 3 species, Plesiomonas shigelloides, Aeromonas hydrophila and Aeromonas sp. which was resistant to $\mathrm{O} / 129$ and could not be identified by the system.

\section{Microflora of the Diet for Frogs}

The maximum viable counts of the bacteria belonging to different components of the millworm were shown in Table 1. Pseudomonas, $E$. agglomerans, $S$. marcescens and coryneforms were 
predominant. No obligate anaerobes were detected. Total viable count which was calculated by summing up the maximum viable counts of each bacterial component was $10^{7} \mathrm{~g}^{-1}$.

Intestinal Microflora of the Tadpole, Metamorphosing Tadople and Frog

In the intestinal tracts of tadpole, obligately anaerobic bacteria, Bacteroidaceae including $\mathrm{Bac}$ teroides A-like, helically coiled rods and filamentous rods were predominant as presented in Table 2. Pseudomonas, A. hydrophila, pin-hole colony formers and Bacteroidaceae were detected in all specimens. TVC of each specimen was $10^{8} \mathrm{~g}^{-1}$.

In the intestinal tracts of metamorphosing tadpoles, major components consisted of Bacteroides A-like, other Bacteroidaceae, Clostridium and pin-hole colony formers as shown in Table 3. Pseudomonas, pin-hole colony formers, Bacteroides A-like and other Bacteroidaceae were detected in

Tlabe 1. Viable counts (log No. $\mathrm{g}^{-1}$ ) of the bacteria belonging to different genera of millowarm Tenebrio molitor

\begin{tabular}{lc}
\hline \multicolumn{1}{c}{ Component } & Viable Counts \\
\hline Pseudomonas & 6.52 \\
Enterobacter agglomerans & 6.81 \\
Serratia marcescens & 6.81 \\
Flavobacterium & 5.76 \\
Coryneforms & 6.77 \\
Yeasts & 3.26 \\
\hline TVC & 7.04 \\
\hline
\end{tabular}

all specimens. TVC ranged from $10^{8}$ to $10^{9} \mathrm{~g}^{-1}$.

In the large intestinal tracts of frogs, dominant components were composed of Bacteroidaceae and Clostridium as presented in Table 4. Pseudomonas, pin-hole colony formers and Bacteroides A-like, which were major components in the tadpole and metamorphosing tadpole, decreased and partly disappeared. Alternatively, various enterobacteria, C. freundii, C. diversus, E. coli, E. hafniae, $K$. pneumoniae and $A$. hinshawii, and $P$. shigelloides predominated with occurrence of $80 \%$.

\section{Discussion}

In previous papers, ${ }^{1-3,14,15)}$ we reported that predominant bacterial components in the gastrointestinal tracts of freshwater fishes are $A$. hydrophila, $P$. shigelloides, Pseudomonas, Enterobacteriaceae, Bacteroides type A and Bacteroides type B, whereas those of soft-shelled turtles were $A$. hydrophila, $P$. shigelloides, C. freundii, Edwardsiella tarda, Streptococcus faecalis, Bacteroidaceae (not included Bacteroides type A and type B) and Clostridium. Such differences in gastrointestinal flora of animals seem to be associated with diets, physiological conditions and species of host animals. The predominant flora of tadpoles of Bullfrog was composed of Pseudomonas, $A$. hydrophila, pin-hole colony formers, Bacteroides A-like and other Bacteroidaceae although $\boldsymbol{P}$. shigelloides, Flavobacterium, various enterobacteria, Bacteroidaceae (not included Bacteroides Alike) and Clostridium were predominant in frogs

Table 2. Viable counts $\left(\log N o . \mathrm{g}^{-1}\right)$ of the bacteria belonging to different genera in the contents of intestinal tracts of tadpoles

\begin{tabular}{lccccc}
\hline \multirow{2}{*}{ Component } & \multicolumn{5}{c}{ Viable Counts of Specimen } \\
\cline { 2 - 6 } & 1 & 2 & 3 & 4 & 5 \\
\hline Pseudomonas & 6.82 & 5.88 & 7.08 & 5.15 & 5.91 \\
Aeromonas hydrophila & 6.56 & 5.66 & 5.30 & 5.93 & 5.08 \\
Aeromonas sp. & 5.60 & - & 5.30 & - & - \\
Citrobacter diversus & $-*$ & - & - & 4.60 & - \\
Enterobacter cloacae & - & - & - & - & 4.30 \\
Pin-hole colony formers & 6.56 & 6.30 & 7.04 & 6.18 & 6.00 \\
Bacillus & - & - & 5.08 & 5.00 & 4.78 \\
Micrococcus & - & - & 5.30 & - & 3.30 \\
Bacteroides A-like & 8.00 & 7.44 & 8.11 & - & 7.38 \\
Bacteroidaceae & 8.58 & 8.15 & 8.43 & 8.56 & 8.75 \\
Helically coiled rods & 7.78 & - & - & 7.30 & 6.30 \\
Filamentous rods & 7.30 & - & 7.96 & 8.15 & - \\
Clostridium & - & - & - & 7.30 & 6.30 \\
\hline TVC & 8.76 & 8.23 & 8.72 & 8.73 & 8.77 \\
\hline
\end{tabular}

- Not detected. 
Table 3. Viable counts $\left(\log\right.$ No. $\left.\mathrm{g}^{-1}\right)$ of the bacteria belonging to different genera in the contents of intestinal tracts of metamorphosing tadpoles

\begin{tabular}{|c|c|c|c|c|c|}
\hline \multirow{2}{*}{ Components } & \multicolumn{5}{|c|}{ Viable Counts of Specimen } \\
\hline & 1 & 2 & 3 & 4 & 5 \\
\hline Pseudomonas & 5.90 & 5.93 & 5.60 & 5.78 & 3.30 \\
\hline Aeromonas hydrophila & -* & - & - & - & 5.60 \\
\hline Aeromonas sp. & - & 一 & 4.11 & - & 5.08 \\
\hline Plesiomonas shigelloides & - & 4.78 & - & 6.80 & 5.70 \\
\hline Moraxella & 6.45 & - & 7.38 & - & - \\
\hline Acinetobacter & - & 4.30 & - & 5.94 & 3.30 \\
\hline Flavobacterium & - & - & - & 5.00 & - \\
\hline Citrobacter freundii & 5.90 & - & - & - & 5.30 \\
\hline Klebsiella ozaenae & - & 3.30 & 5.30 & - & - \\
\hline Escherichia coli & - & - & - & 4.60 & - \\
\hline Pin-hole colony formers & 7.30 & 6.49 & 7.51 & 6.85 & 7.30 \\
\hline Bacillus & 5.41 & 3.90 & - & 6.00 & - \\
\hline Micrococcus & - & - & - & 5.66 & 3.30 \\
\hline Staphylococcus & - & - & 2.30 & - & - \\
\hline Streptococcus & - & - & 3.30 & - & - \\
\hline Coryneforms & - & - & 6.41 & 4.30 & - \\
\hline Bacteroides A-like & 6.30 & 6.60 & 7.60 & 6.51 & 8.15 \\
\hline Bacteroidaceae & 8.11 & 8.62 & 8.48 & 7.94 & 8.91 \\
\hline Filamentous rods & - & 6.60 & - & - & - \\
\hline Clostridium & 7.15 & 7.30 & - & 7.92 & 7.90 \\
\hline TVC & 8.23 & 8.65 & 8.60 & 8.26 & 9.04 \\
\hline
\end{tabular}

* Not detected.

Table 4. Viable counts $\left(\log\right.$ No. $\left.\mathrm{g}^{-1}\right)$ of the bacteria belonging to different genera in the contents of large intestinal tracts of frogs

\begin{tabular}{|c|c|c|c|c|c|}
\hline \multirow{2}{*}{ Component } & \multicolumn{5}{|c|}{ Viable Counts of Specimen } \\
\hline & 1 & 2 & 3 & 4 & 5 \\
\hline Pseudomonas & -* & 7.26 & - & 6.78 & - \\
\hline Aeromonas hydrophila & - & - & 5.85 & 5.15 & - \\
\hline Plesiomonas shigelloides & 6.90 & - & 6.20 & 7.20 & 7.15 \\
\hline Flavobacterium & 5.30 & -- & 6.20 & 6.30 & 6.15 \\
\hline Citrobacter freundii & 6.30 & - & 7.08 & 7.66 & 6.90 \\
\hline Citrobacter diversus & 6.60 & 6.60 & 6.56 & - & 7.56 \\
\hline Escherichia coli & 8.28 & 8.44 & 7.11 & 7.58 & 7.88 \\
\hline Enterobacter hafniae & 6.41 & 6.30 & - & 5.51 & 6.30 \\
\hline Klebsiella pneumoniae & 7.98 & 8.48 & 6.82 & 6.36 & - \\
\hline Klebsiella ozaenae & - & 7.26 & - & - & - \\
\hline Arizona hinshawii & 6.90 & 7.56 & 5.53 & - & 7.75 \\
\hline Serratia marcescens & - & - & - & 6.30 & - \\
\hline Pin-hole colony formers & 一 & - & 6.20 & - & - \\
\hline Bacillus & 6.72 & - & 5.78 & - & - \\
\hline Micrococcus & - & - & 4.60 & - & - \\
\hline Bacteroidaceae & 7.66 & 9.41 & 8.80 & 9.30 & 8.74 \\
\hline Filamentous rods & - & - & - & 8.11 & - \\
\hline Clostidium & 8.04 & 8.11 & 8.52 & 8.73 & 7.58 \\
\hline TVC & 8.66 & 9.49 & 9.00 & 9.45 & 8.90 \\
\hline
\end{tabular}

* Not detected. 
after metamorphosis. The intestinal flora of metamorphosing tadpoles consisted of Pseudomonas, pin-hole colony formers, Bacteroides Alike, other Bacteroidaceae and Clostridium, and it would be the transit form when the intestinal bacteria of tadpoles changed and adapted to frogs.

As compared the intestinal flora of Bullfrog at each developmental stage with those of other animals, it is found that the microflora of tadpoles is similar to that of freshwater fishes while the microflora of frogs resembles that of soft-shelled turtles or higher animals. ${ }^{1 \text { i) }}$

In the present study the boiled spinach and millworm were fed to Bullfrog. The spinach would have no bacteria or, even though present, a few sporing bacteria because of heat treatment. In the large intestines of frogs fed the millworm, Pseudomonas, Flavobacterium and S. marcescens were common to its diet. However, Pseudomonas and Flavobacterium are suspected not to originate from the millworm because these bacteria are isolated from the tadpole and metamorphosing tadpole. VAN DER WAAIJ et al. reported that potentially pathogenic bacteria in cloacal contents of Leopard frog Rana pipiens seem to originate from the diets, so the $S$. marcescens has the possibility to originate from the millworm.

Nevertheless, the significant succession of microflora in the intestinal tracts of Bullfrog should be reflecting the physiological changes of host animals. That is, the intestine shortens from 6-8 times to $1.5-2$ times body length, their habitat changes from water to land and food habit changes from omnivorous to carnivous type. At the present time it is impossible to define which is the major factor to change the intestinal flora of Bullfrog. However, it is clear that frogs is an important experimental animal to study the interaction between the intestinal fiora and host animals.

From the intestines of tadpoles and metamorphosing tadpoles, a bacterium silimar to Bacteroides type A was isolated. Although we did not clarify whether this is identical to Bacteroides type A, it may be an important object to study the ecology of Bacteroides type A. The taxonomic study concerning this bacterium should be required.

\section{Acknowledgements}

We wish to express our gratitude to Dr. N. TANAKA, National Research Institute of Aquaculture for his valuable suggestions.

\section{References}

1) H. Sugita, A. Enomoto, and Y. Deguchi: Bull. Japan. Soc. Sci. Fish., 48, 875 (1982).

2) H. Sugita and Y. Deguchi: Bull. Japan. Soc. Sci. Fish., 49, 197-201 (1983).

3) H. Sugita, K. Oshima, M. Tamura, and Y. DeguchI: Bull. Japan. Soc. Sci. Fish., 49, 1387 1395 (1983).

4) R.T.J. Clarke and T. Bauchop (ed.): Microbial Ecology of the Gut, Academic Press, London, 1977, pp. 1-410.

5) D. VAn der WaAis, B. J. Cohen, and G. W. NACE: Lab. Anim. Sci., 24, 307-317 (1974).

6) J. C. Glorioso, R. L. AMBorski, G. F. AMBorski, and D. D. Culley: Am. J. Vet. Res., 35, 12411245 (1974).

7) J. Gosstung, W. J. LoEsche, and G. W. NACE: Appl. Environ. Microbiol., 44, 59-66 (1982).

8) J. Gossling, W. J. Loesche, and G. W. NACE: Appl. Environ. Microbiol., 44, 67-71 (1982).

9) T. Mrtsuoka: in "Kansen Moderu no Kumikata", Kindai Pub., Tokyo, 1973, pp. 165-192.

10) H. Sugita, H. TanaAmi, T. Kobashi, and Y. DeguchI: Bull. Japan. Soc. Sci. Fish., 47, 655661 (1981).

11) J. M. Shewan, G. Hobrs, and W. Hodgkiss: $J$. Appl. Bacteriol., 23, 379-390 (1960).

12) S. T. Cowan: Cowan and STEel's Manual for the Identification of Medical Bacteria, 2nd ed., Cambridge University Press, London, 1974, pp. 1-238.

13) T. Sakata, H. Sugita, T. Mitsuoka, D. KaKIMOTO, and H. KaDOTA: Bull. Japan. Soc. Sci. Fish, 47, 421-427 (1981).

14) H. Sugita, T. Sakata, Y. Ishida, Y. Deguchi, and H. Kadota: Bull. Coll. Agr. Vet. Med., Nihon Univ., 38, 302-306 (1981).

15) H. Sugita, T. Sakata, Y. Ishidd, Y. Deguchi, and H. KaDOTA: The Aquiculture, 31, 191-195 (1984).

16) T. MitsuoKa and C. Kaneuchi: Am. J. Clin. Nutr., 30, 1799-1810 (1977). 